\title{
Application of Data Mining in Designing a Recommender System on Social Networks
}

\author{
Saman Forouzandeh \\ Young Researchers and Elite \\ Club, Sardasht Branch, Islamic \\ Azad University, Sardasht, Iran \\ Young Researchers and Elite \\ Club, Urmia Branch, Islamic \\ Azad University, Urmia, Iran.
}

\author{
Heirsh Soltanpanah \\ Department of Industrial \\ Engineering, Sanandaj Branch, \\ Islamic Azad University, \\ Sanandaj, Iran.
}

\author{
Amir Sheikhahmadi \\ Department of Computer \\ Engineering, Sanandaj Branch, \\ Islamic Azad University, \\ Sanandaj, Iran.
}

\begin{abstract}
The prevalence of social networks amongst people has become an inevitable issue. At the same time, social networks have widely been used for commercial purposes. As a result, in order to sell the products, social networks have been equipped with various recommender systems that provide the users with commercial offers that are appropriate for their behavior. The accuracy of the recommender systems in providing offers to the users and the number of offers accepted by the users are crucial issues. In the present study, a recommender system was designed that operates based on the users' behavior on Facebook and in two phases offers the users to buy their favorite products. In the first phase, the users' behavior is investigated and based on their interest they are offered to buy some products. In the second phase, the recommender system uses data mining techniques and provides the users with offers that are relevant to their previous purchase. The data of the study are factual and the results are valid. Moreover, the results indicate that the designed recommender system is highly accurate in providing offers to the users.
\end{abstract}

\section{Keywords}

Social Networks, Data Mining, Recommender Systems, Association Rules

\section{INTRODUCTION}

In social networks, individuals make friends with each other and everyone possesses a profile. Depending on the social network, the profile contains relevant information that increasingly helps the marketers offer different products according to the users' preferences. What is required to sell the products of different companies is appropriate advertisement of the products according to the needs of the users in these social networks. Lack of knowledge about the users and their interests is one of the reasons for the failure of the marketers and the advertisement. Therefore, and due to the rapid transfer of information and presence of large amounts of data in social networks, it is necessary to utilize systems that will customize the Internet for the users. These systems are called recommender systems that according to the users' behavior offer them to buy products or use services. These systems help the users to find the product(s) that they tend to buy. In these cases, the offer is made based on the clients' preferences (Galvao, 2010). Facebook is one of the most popular social networks. There are more than 500 million active Facebook users and at least half of them log in to their account everyday [1]. This means that you have access to the individuals' profiles and can make decisions about them and how to present your products to them. The present study follows paper [2] in which content marketing for Facebook users was investigated and through techniques of data mining, the user's likes on the provided content were recorded. The present study is also aimed at designing a recommender system that identifies the users' needs according to their interests and offers them to buy a product that is highly compatible with their needs and wills. Here, based on the likes given by the users, the designed recommender system provides the users with offers in two phases. In the first phase, the user's likes are compared to his profile and any product that has the highest compatibility with the profile will be offered to him. In the second phase, by utilizing data mining techniques and association rules, the behavior of the users who have purchased at least once will be examined and they will be offered to buy another product which is first in line with the first product and second similar to the user's behavior.

\section{REVIEW OF THE LITERATURE}

A large body of research has been carried out on the issue, some of which are reviewed here. Research [3] is an investigation into marketing in social networks, in which a recommender system was devised, each user's information was classified based on data mining techniques, and the users were provided with offers according to their interests. In paper [4], the researchers studied the data on Twitter. In this study, a recommender system was designed, in which offers were made based on the level of the users' popularity, influence, and activity on Twitter. Another paper is [5] where a website was set up to do electronic business. In this website, the users were provided with offers according to the related data collection and analysis. The data were retrieved from the users' Facebook profiles. paper [6] recommended using the users' profiles in social networks in order to provide them with appropriate offers. In research study [7], using recommender systems was introduced as a necessity and the theory of six degrees of separation (Watts, 2003) was utilized to promote the recommender system in social networks. In paper [8] the users' cell phones were utilized to provide the users of the social networks with offers. The offers were made with the recommender system based on the users' place of residence. In research [9], product marketing was based on the individuals' influence which was considered in the designed recommender system that found highly influencing individuals based on specific criteria and they were provided with product marketing. In paper [10], an expert recommender system was 
designed and combined recommender systems that offered the users according to the content of their profile. In paper [11], they focus on POI recommendation by exploring the ratings and their corresponding time stamps on LBSN. Different from conventional methods, they aim to model user rating behavior for learning user preferences through exploring the comparative choices within a certain period. They devise a collection - wise learning method over partial orders through an effective stochastic gradient descent algorithm. Experiments conducted on two real world datasets have demonstrated that their approach outperform existing methods.

\section{METHOD}

As mentioned, in paper [2] content marketing was utilized to present different contents to the users and each content represented a product whereby the user was given necessary knowledge that helped him to know the reasons for using the product; therefore, he got motivated to buy it. In the second phase, by using data mining techniques, the users' behavior was pursued and their likes on different posts were recorded. It was also stated that the users' likes on each content indicated their interest to it. In the present study, a recommender system is designed according to the users' behavior, which in the first phase examines the users' likes. In so doing, a designed metadata is defined for each content, product, or service that will be offered to the users. For the products of the metadata, five fields as the conditions of using the products are considered according to the users' profiles. Those five fields are retrieved from the users' profiles and compared to each other through the designed recommender system and the products that are more alike will be offered to the user.

In the second phase, association rules are utilized to provide the users with offers. In this phase, the users who have purchased at least once will be given another purchase offer. The second purchase is in line with the previous one. That is the products are classified and the ones that are in the same group are related items and can be utilized together. Therefore, in the second phase, a product will be offered to the user that possesses the following conditions:

- The offered product is in the same group that the user bought from.

- A different user who previously bought the product has the highest behavioral similarity in regard with content liking with the target user.

\section{DESIGNING THE RECOMMENDER SYSTEM IN THE FIRST PHASE BASED ON THE USERS' BEHAVIOR}

In this section, content-based recommender systems are utilized and the content-based filtering ideology is to distinguish which item the current user likes. In these systems, every user acts independently and the data are retrieved a system that is derived from the content of the documents and the items [12]. Independence of each user in this method means that every user has his own unique preferences and creates his priority model. This model is independent from other users' priority models and its quality depends on the retrieved characteristics. In this model, the characteristics that are considered for the products are highly important and the aim is that if the characteristics are similar to the users' preferences, then the product will be offered to him. A new product can also be modeled and compared for the user according to previously defined characteristics [13]. This means that there is no limitation for the user and new products are compared to the user's characteristics and if they are similar, he will be offered the product. Implementation of content-based recommender systems is an approach that is based on analysis of documents and items that are previously ranked by the user and the model that is created by the user is used to offer him according to the items that are previously ranked by him [14]. In the present study, items are ranked based on the users' likes; that is when content is liked by a user, he will gain necessary knowledge about it and if he is suggested about the advantages and purchase of the item, this offer will be based on the user's previous knowledge [2]. Ranking items is based on like/dislike which is called binary ranking because there are only two states [14]. This type of ranking is highly compatible with Facebook since the users' preferences are based on liking the contents. After the target content is presented to the users and the likes are recorded [2], the users' likes are analyzed based on their profiles and five fields are considered in their profiles including 1) gender, 2) marital status, 3) age, 4) education, and 5) place of residence. For each product related to the content, five fields are considered as usage conditions that is every product is compared to the user's profile and those that are highly appropriate to his profile will be offered to him. Conditions of using the products are based on the fields of the user's profile and comparison is carried out accordingly. When the product is referred to, the target fields are displayed and comparison of the user's profile with the fields is made one by one and the result is showed numerically. The procedure of encoding the fields is showed in Table 1 below.

Table 1. Encoding the fields that are written as a continuum

\begin{tabular}{|l|l|l|l|l|l|l|}
\hline Fields & State 1 & Code & State 2 & Code & State 3 & Code \\
\hline Gender & Female & 0 & Male & 1 & - & - \\
\hline $\begin{array}{l}\text { Marital } \\
\text { Status }\end{array}$ & Single & 0 & Married & 1 & - & - \\
\hline Age & $\begin{array}{l}\text { Less } \\
\text { than 20 }\end{array}$ & 0 & $\begin{array}{l}\text { Between } \\
\text { 30 and }\end{array}$ & 1 & Over 30 & 2 \\
\hline Education & $\begin{array}{l}\text { Less } \\
\text { than } \\
\text { Diploma }\end{array}$ & 0 & Diploma & 1 & University & 2 \\
\hline $\begin{array}{l}\text { Place of } \\
\text { esidence }\end{array}$ & $\begin{array}{l}\text { Out of } \\
\text { the } \\
\text { Country }\end{array}$ & 0 & $\begin{array}{l}\text { In the } \\
\text { Country }\end{array}$ & 1 & - & - \\
\hline
\end{tabular}

Afterwards, dissimilarity matrix is utilized to compare the user's profile with usage conditions. This matrix specifies the distance or dissimilarity of two things and usually has an $n * n$ form. $d(I, j)$ is the considered amount to show dissimilarity between items $\mathrm{i}$ and $\mathrm{j}$. Distances are good criteria to show similarities or dissimilarities [15]. In order to calculate the difference between the variables, the distance between them is measured. In this study, Manhattan Distance is utilized that is as follow [14][15]:

$d(i, j)=\left|X_{i 1}-X_{j 1}\right|+\left|X_{i 2}-X_{j 2}\right|+\ldots+\left|X_{i p}-X_{j p}\right|$ 
Data need to be normalized and the matrices should be given the same rank and then compared with each other. In so doing, they should be separated and compared line by line with the user's profile. The results show that the more the distance is, the more distant and more dissimilar the two matrices are. And if the distance is zero, the two matrices are equal. The procedure is like this first a two-dimensional matrix is designed. The rows of the matrix stand for the number of likes given by the user and in each row is filled with a product each of which has 5 columns (according to the fields retrieved from the user's profile). The designed matrix is initialized with codes presented in Table 1. Five fields are also considered from the user's profile, which creates a matrix with one row and five columns. The resulting matrix from the user's profile is compared to the matrix of his likes field by field and their distance is measured and if they are similar, their distance is considered as 0 ; otherwise, the distance for each field is considered as 1 . And finally, a matrix that has the shortest distance compared to the matrix of the user's profile, that product or service will be the best option to be offered to the user. For example, the matrix of the user X's likes is presented in Table 2. The first row presents the user's characteristics and the rest five rows indicate the user X's likes each of which stands for a specific product. The calculated distance between the user's profile and the liked products are presented in the last column of the table.

Table 2. Encoding the fields that are written as a continuum

\begin{tabular}{|c|c|c|c|c|c|c|}
\hline & $\begin{array}{l}\text { Place of } \\
\text { Residence }\end{array}$ & Education & Age & $\begin{array}{l}\text { Marital } \\
\text { Status }\end{array}$ & Gender & Distance \\
\hline $\begin{array}{c}\text { User } \\
\mathbf{X}\end{array}$ & 1 & 2 & 1 & 0 & 1 & \\
\hline $\mathbf{A}$ & 1 & 2 & 0 & 0 & 0 & 2 \\
\hline B & 1 & 2 & 1 & 0 & 1 & 0 \\
\hline $\mathbf{C}$ & 0 & 1 & 0 & 1 & 1 & 4 \\
\hline D & 1 & 2 & 2 & 0 & 1 & 1 \\
\hline E & 1 & 2 & 0 & 1 & 0 & 3 \\
\hline
\end{tabular}

For example, for Like A, the distance for the product with the user's profile is calculated through Manhattan Distance formula as follow:

$A=|1-0|+|0-0|+|1-0|+|2-2|+|1-1|=1+1=2$

The calculated figure indicates the number of the fields that are different. For Like A, the result indicates that the conditions of the products in two fields are not similar with the user's profile. According to the results, the user's Like B has the highest degree of similarity and its distance is zero. This means that the user's matrix and the conditions of using product B are not dissimilar at all; therefore, this product can be the best option to be offered to the user to buy.

As mentioned, in the defined matrix to measure dissimilarity between the user's profile and the products, the difference between each code should be one unit so as to clarify the number of fields with dissimilarity. However, in some cases the difference is 2 units. To correct this error in comparing the codes, two floor functions are defined and are utilized according to the user's code or those of the products. In the field related to the user where there are two states of product codes namely 0 or 2 , it is possible that an error occurs and the dissimilarity between the two fields is more than 1 . To solve this problem, a separate function is defined for each state. It is noteworthy that in the defined functions, their first state changes 2 to 1 in order to reduce the two-unit difference between the corresponding fields. And in their second state, zero is changed into 1 . These functions are presented below. An example is also provided for each one.

$$
\begin{aligned}
& 1-\mathrm{f}(\mathrm{x})=\left[\frac{\mathrm{x}}{2}+\frac{1}{2}\right]: \\
& \left\{\begin{array}{c}
\text { If } \mathrm{x}=2 \rightarrow \mathrm{f}(2)=\left[\frac{2}{2}+\frac{1}{2}\right]=[1.5]=1 \\
\text { If } \mathrm{x}=1 \rightarrow \mathrm{f}(1)=\left[\frac{1}{2}+\frac{1}{2}\right]=[1]=1 \\
\text { If } \mathrm{x}=0 \rightarrow \mathrm{f}(0)=\left[\frac{0}{2}+\frac{1}{2}\right]=[0.5]=0
\end{array}\right. \\
& 2-\mathrm{g}(\mathrm{x})=\left[\frac{\mathrm{x}}{2}+1\right]: \\
& \left\{\begin{array}{c}
\text { If } \mathrm{x}=2 \rightarrow \mathrm{g}(2)=\left[\frac{2}{2}+1\right]=[2]=2 \\
\text { If } \mathrm{x}=1 \rightarrow \mathrm{g}(1)=\left[\frac{1}{2}+1\right]=[1.5]=1 \\
\text { If } \mathrm{x}=0 \rightarrow \mathrm{g}(0)=\left[\frac{0}{2}+1\right]=[1]=1
\end{array}\right.
\end{aligned}
$$

Therefore, by applying the functions in all states, the distance between the matrix of the user's fields and those of the products will not be more than 1 and no error will occur in the final outcome. As a result, these functions enhance the accuracy of the designed recommender system.

\section{DESIGNING THE RECOMMENDER SYSTEM TO PROVIDE THE USER WITH THE SECOND OFFER}

In this phase, the user who has purchased at least once is offered to buy a product. In so doing, association rules are applied. Association rules are analyzed in order to achieve strong rules with high level of confidence. Here, the users' likes that have led them to buy products are examined and comparison is conducted for different users so as to achieve the level of their similarity in liking the contents. In the present study, it is supposed that the users who have given the same likes have similar interests and needs.

In this phase, the designed recommender system operates based on associative filtering and provides the users with some offers according to their similarity. Offers are based on behavioral similarities in liking the contents and those who have the highest level of similarity and whose purchases are in the same categories of products are identified by the associative recommender system and provided with the offer of buying a product purchased by another user who has the highest level of behavioral similarity. In association rules, for variables of $\mathrm{X}$ and $\mathrm{Y}$ and the way they are related, there are two terms namely support and confidence that are defined below. Support indicates the percentage or the total transactions of D that includes both variables of $\mathrm{X}$ and $\mathrm{Y}$ [5]. Confidence explains the level of dependence of a particular product on another one, which is calculated through the following formula [5].

Confidence $(X \Rightarrow Y)=P(Y \mid X)=\frac{\operatorname{Support}(X \cup Y)}{\operatorname{Support}(X)}$ 
This criterion calculates the correlation between the sets of $X$ and Y. And a criterion is considered to measure the power of a rule. Mostly, rules that have big confidence coefficients are chosen. The criteria of support and confidence rules indicate their attractiveness. After the relation between the sets is analyzed, these two criteria indicate the level of confidence and the usefulness of the rules, respectively. If a set of rules has the minimum support, they are called frequent. Strong rules are the rules that frequently have support and confidence levels more than the threshold level. In the present study, Apriori algorithm is applied to analyze association rules and find these rules. This algorithm measures the database once and removes extra items and does not enter the next phase [15]. An important issue that should be noted is in regard with choosing the users to analyze their likes through association rules. In order to delimit the number of the users in order to pursue their likes, define the number of function of analyzing association rules, and enhance the accuracy of the association rules, a metadata of the experts, producers, and service providers' opinion about the products and services used to define complements. In so doing, for each product it is identified which products or services accompanies them and what needs a user will have after buying a product. Therefore, the users who have bought something in this time range are identified and their likes are analyzed. In the metadata, the products are classified and those that are in the same groups are complimentary and are often used together. However, it should be noted that identifying the products that are related and which ones are purchased together can be accomplished through association rules [15] and the same analysis is done for the purchased products. The same is also carried out in the present study the only difference is that here the analysis is conducted on the likes instead of the purchased products and the rules are analyzed and new ones are drawn based on the similarity of the user's likes.

To clarify the issue, for example the algorithm is applied for the users who have purchased at least once and according to the results, the outcome is analyzed; therefore, some rules are discovered based on which the users are provided with another offer. A set of five products is considered together that ate bought by five users. The user's likes are examined in order to create new rules and provide other offers. What is considered in the present study to calculate support and confidence includes:

$\mathrm{X} \Rightarrow \mathrm{Y}$ [Support - $60 \%$, Confidence - $60 \%$ ]

Support of $60 \%$ means that $60 \%$ of all of the interactions show that contents $\mathrm{X}$ and $\mathrm{Y}$ are liked together and confidence of $60 \%$ for association rules means that $60 \%$ of the users have liked content $X$ have also liked content $Y$. The set of five products that includes five transactions is formed as follow:

$\mathrm{D}=\left\{\mathrm{T}_{1}, \mathrm{~T}_{2}, \mathrm{~T}_{3}, \mathrm{~T}_{4}, \mathrm{~T}_{5}\right\}$

Each transaction indicates a purchased products and the content the user has liked which has resulted in buying the product. In Figure 1, the procedure explained in Tables A-H is displayed separately.

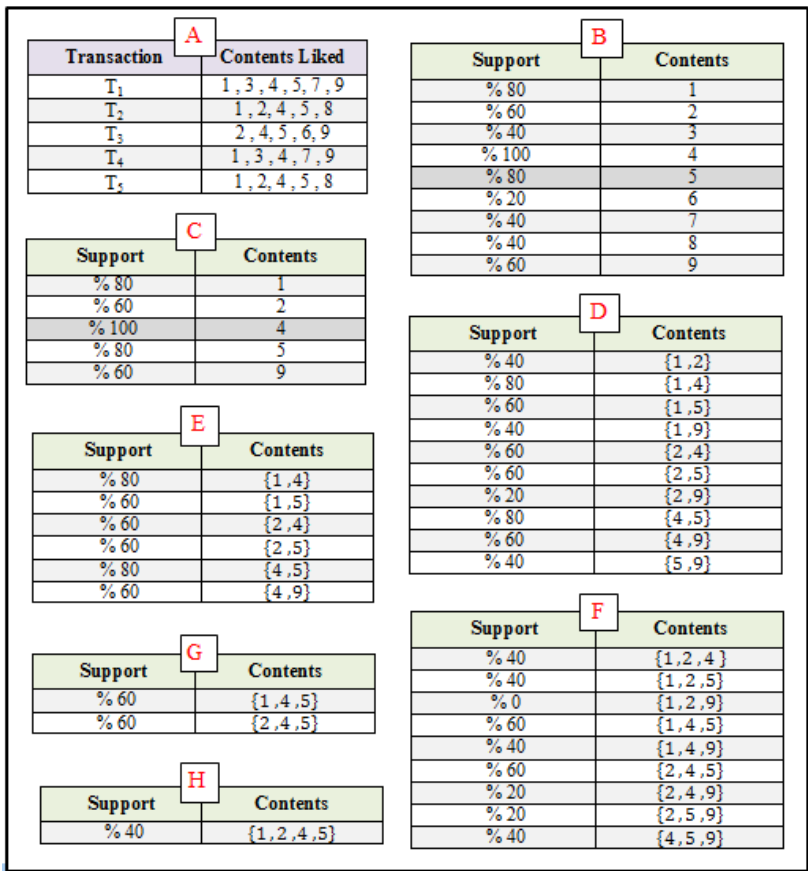

Fig 1: The procedure of support conduction to gain the target content

In Table $\mathrm{A}$, the transactions are indicated each of which stands for the likes given by the users who have bought some products that are categorized in one group. Finally, in Table $\mathrm{H}$ a group of four contents is gained and the items cannot be combined more than this. Therefore, the highest level of behavioral similarity belongs to the users who have bought products $T_{2}$ and $T_{5}$ and this means these two users have bought different products, they have four similar likes. In the next phase, the rate of confidence is calculated for the rules gained from Table $\mathrm{H}$ as follow:

$$
\begin{aligned}
& (1 \rightarrow 2)=p(2 \mid 1)=50 \% \quad-(1 \rightarrow 4)=p(4 \mid 1)=100 \% \\
& (1 \rightarrow 5)=p(5 \mid 1)=66 \% \quad-(2 \rightarrow 4)=p(4 \mid 2)=100 \% \\
& (2 \rightarrow 5)=p(5 \mid 2)=100 \%-(4 \rightarrow 5)=p(5 \mid 4)=80 \%
\end{aligned}
$$

According to the considered threshold for the confidence, only the rule $(1 \Rightarrow 2)$ is removed. From the rules gained in Table $\mathrm{H}$, only one of them has an amount less than the threshold and the rest have the require condition. Therefore, $\left(\frac{5}{6}=83 \%\right)$ of the likes have the minimum confidence level. This is also an indication for the strength of the extracted rules. Therefore, the purchases of the users $T_{2}$ and $T_{5}$ can be recommended to one another, i.e. the user $T_{2}$ can be offered to buy the product purchased by the user $\mathrm{T}_{5}$ and the user $\mathrm{T}_{5}$ can be offered to buy the product purchased by the user $T_{2}$.

\section{THE DESIGNED METADATA}

In this section, a sample of the designed metadata for the present study is presented. The metadata is defined in the form of a table. By liking each content that is presented to the user, information that is extractable from the table is showed in Table 3. Therefore, by applying the above-presented table, the users' likes can easily be pursued and they can be offered to buy different products in two stages. 


\section{EVALUATING THE PROPOSED METHO}

\subsection{Evaluating the accuracy of the recommender system in providing the users with offers}

To evaluate the accuracy of the designed recommender system, 10 Facebook accounts have been examined and a total of 185 contents in fields like sports, health, book, music, movies, and technology have been presented to 3500 users and their behavior has been examined according to their likes on the contents. A total of 580 purchase offer have been given to the users. Offers are provided this way; if they user accepts the first offer, then the second offer will be given. In Table 4, the way the recommender system is evaluated in regard with offering the users in technology field is presented. Twenty different contents each of which presents a particular product in technology field are presented to the users and they were given 100 offers. Each user's profile and the product that has the highest level of similarity with them is encoded according to Table 1. Afterwards, the target product is presented to the user in two phases. A part of the users' acceptance or rejection is presented in Table 4 .

This procedure has been applied for the other fields. Therefore, the effectiveness of the method in all of the fields can be evaluated. The total results of evaluating the recommender system for all of the contents presented to the users are displayed in Table 5 and Figure 2.

As seen, a total of 580 offers in different fields are presented to the users. In the first phase, $87 \%$ of the offers are accepted and in the second phase the users who have accepted the first offer are provided with the second offer and $83 \%$ of the users have accepted it. In Table 5, the results of the offers are presented for any of the abovementioned fields. For example, in the field of health, 45 contents are presented to the users and then 55 offers are given to them according to their likes. In the first and second phases, $80 \%$ and $87 \%$ of these offers are accepted by the users, respectively. The results indicate that the accuracy of the designed recommender system is acceptable in both phases and most of the users have accepted the offers provided by the system.

Table 3. A sample of the defined metadata for the content presented to the user

\begin{tabular}{|l|l|l|l|l|l|l|l|l|l|}
\hline $\begin{array}{l}\text { Products that are related and } \\
\text { in the same group as the } \\
\text { offered one }\end{array}$ & \multicolumn{2}{|l|}{$\begin{array}{l}\text { Usage conditions of } \\
\text { the product }\end{array}$} & $\begin{array}{l}\text { The product } \\
\text { considered for each } \\
\text { content }\end{array}$ & $\begin{array}{l}\text { Content } \\
\text { grouping }\end{array}$ & $\begin{array}{l}\text { The content } \\
\text { liked by the } \\
\text { user }\end{array}$ \\
\hline $\mathbf{T}_{\mathbf{2}}, \mathbf{T}_{\mathbf{3}}, \mathbf{T}_{\mathbf{6}}, \mathbf{T}_{\mathbf{1 1}}$ & 1 & 2 & 0 & 1 & 0 & Product T1 & A & Content 1 \\
\hline $\mathbf{T}_{\mathbf{7}}, \mathbf{T}_{\mathbf{8}}, \mathbf{T}_{\mathbf{1 4}}$ & 1 & 0 & 1 & 0 & 1 & Product T4 & $\mathrm{C}$ & Content 8 \\
\hline $\mathbf{T}_{\mathbf{1}}, \mathbf{T}_{\mathbf{3}}, \mathbf{T}_{\mathbf{6}}, \mathbf{T}_{\mathbf{1 1}}$ & 0 & 1 & 0 & 1 & 1 & Product T2 & F & Content 16 \\
\hline $\mathbf{T}_{\mathbf{4}}, \mathbf{T}_{\mathbf{8}}, \mathbf{T}_{\mathbf{1 4}}$ & 0 & 2 & 2 & 1 & 0 & Product T7 & $\mathrm{B}$ & \\
\hline
\end{tabular}

Table 4. Accepted offers by the users in technology field

\begin{tabular}{|c|c|c|c|c|c|c|c|c|c|c|c|c|c|c|}
\hline \multirow{2}{*}{$\begin{array}{c}\text { Row } \\
1 \\
\end{array}$} & \multirow{2}{*}{$\begin{array}{c}\text { The content liked by } \\
\text { the user }\end{array}$} & \multicolumn{5}{|c|}{ The user's profile } & \multicolumn{5}{|c|}{$\begin{array}{c}\text { The product offered to } \\
\text { the user }\end{array}$} & \multirow{2}{*}{$\begin{array}{c}\begin{array}{c}\text { Dissimilar } \\
\text { Fields }\end{array} \\
2\end{array}$} & \multirow{2}{*}{$\begin{array}{c}\mathbf{1}^{\text {st }} \\
\text { Offer } \\
\sqrt{ }\end{array}$} & \multirow{2}{*}{$\begin{array}{r}\begin{array}{c}2^{\text {nd }} \\
\text { Offer }\end{array} \\
\times \\
\end{array}$} \\
\hline & & 1 & 1 & 1 & 2 & 0 & 1 & 1 & 1 & 1 & 1 & & & \\
\hline 2 & 8.1217181920 & 1 & 0 & 1 & 2 & 1 & 1 & 0 & 2 & 2 & 1 & 1 & $\sqrt{ }$ & $\sqrt{1}$ \\
\hline 3 & $3,4,5,11,15,16$ & 0 & 0 & 2 & 2 & 1 & 0 & 1 & 0 & 2 & 1 & 2 & $x$ & $x$ \\
\hline ..... & ………......... & $\cdots$ & $\cdots$ & $\cdots$ & $\cdot$ & $\cdots$ & $\cdots$ & $\cdots$ & $\cdots$ & .. & .. & ……............. & $\ldots$ & $\cdots$ \\
\hline 10 & $1,6,14,18$ & 0 & 1 & 0 & 2 & 0 & 0 & 1 & 0 & 2 & 0 & 0 & $\sqrt{ }$ & $\sqrt{ }$ \\
\hline$\ldots .$. & ....................... & $\cdots$ & .. & $\cdots$ & •• & $\ldots$ & $\cdots$ & * & $\cdots$ & .. & .. & …................ & $\ldots$ & $\cdots$ \\
\hline 100 & $2,4,6,7,9,10,17$ & 0 & 0 & 1 & 1 & 1 & 1 & 0 & 1 & 1 & 1 & 1 & $\sqrt{ }$ & $\sqrt{ }$ \\
\hline
\end{tabular}


Table 5. The results of evaluating the recommender system

\begin{tabular}{|c|c|c|c|c|c|c|c|c|c|c|c|c|c|c|}
\hline & \multicolumn{2}{|c|}{ Technology } & \multicolumn{2}{|c|}{ Movies } & \multicolumn{2}{|c|}{ Music } & \multicolumn{2}{|c|}{ Book } & \multicolumn{2}{|c|}{ Health } & \multicolumn{2}{|c|}{ Sport } & \multicolumn{2}{|c|}{$\begin{array}{l}\text { Total } \\
\text { Results }\end{array}$} \\
\hline $\begin{array}{l}\text { Number of the } \\
\text { presented offers }\end{array}$ & \multicolumn{2}{|c|}{100} & \multicolumn{2}{|c|}{150} & \multicolumn{2}{|c|}{120} & \multicolumn{2}{|c|}{70} & \multicolumn{2}{|c|}{85} & \multicolumn{2}{|c|}{55} & \multicolumn{2}{|c|}{580} \\
\hline $\begin{array}{l}\text { Number of } \\
\text { presented content }\end{array}$ & \multicolumn{2}{|c|}{20} & \multicolumn{2}{|c|}{35} & \multicolumn{2}{|c|}{35} & \multicolumn{2}{|c|}{25} & \multicolumn{2}{|c|}{45} & \multicolumn{2}{|c|}{25} & \multicolumn{2}{|c|}{185} \\
\hline $\begin{array}{l}\text { Acceptance of the } \\
\text { first offer }\end{array}$ & $84 \%$ & 84 & $91 \%$ & 137 & $90 \%$ & 108 & $82 \%$ & 58 & $88 \%$ & 75 & $80 \%$ & 44 & $87 \%$ & 506 \\
\hline $\begin{array}{l}\text { Acceptance of the } \\
\text { second offer }\end{array}$ & $82 \%$ & 69 & $80 \%$ & 110 & $78 \%$ & 85 & $87 \%$ & 51 & $92 \%$ & 69 & $84 \%$ & 37 & $83 \%$ & 421 \\
\hline
\end{tabular}

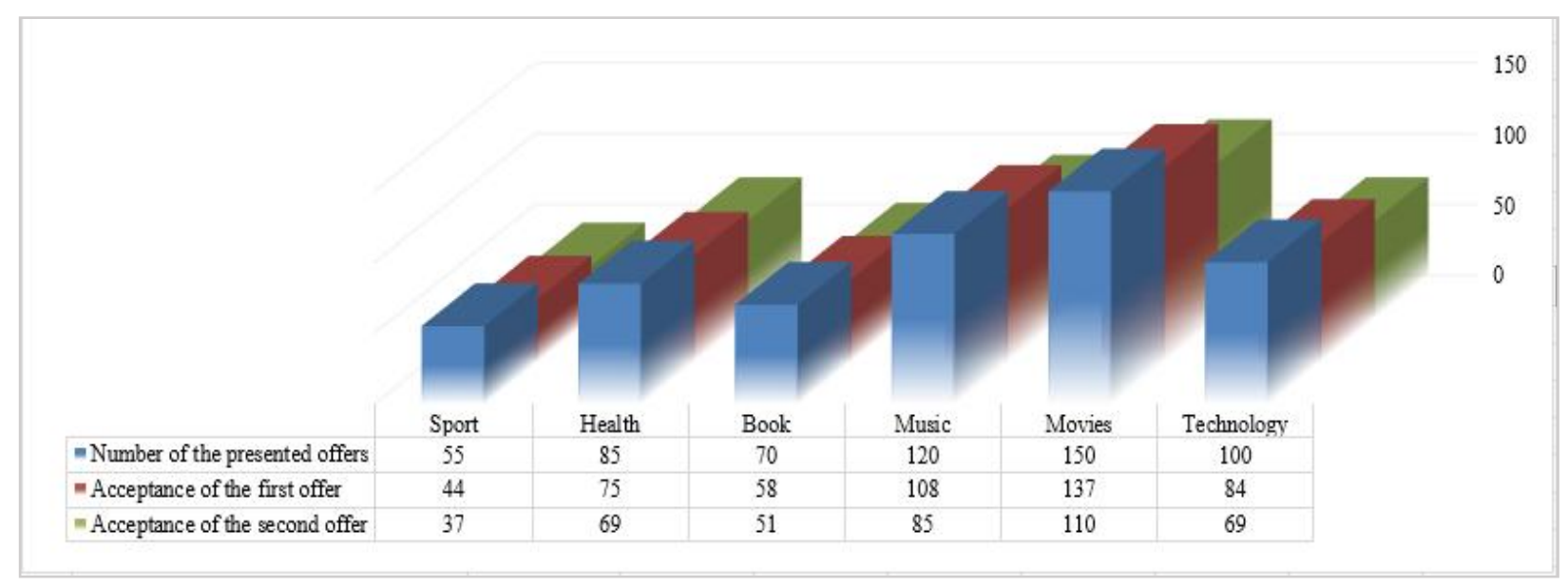

Fig. 2. The diagram of the evaluating the recommender system

\subsection{Evaluating the proposed method through feedback from the users}

In this section evaluation of the proposed method through the users' feedback is discussed. In so doing, 10 Facebook accounts are selected and the survey is given to 2650 users and 2400 users have responded to the survey. The survey includes two questions. The questions are designed in a way that covers all stages of the study. The questions have three options. The results achieved for each question is as follow:

The first question is about the method of offering the products to users in private and public forms. In the first option, it is stated that the users' behavior to be examined and they are offered to buy products according to their behavior and profile. In the second option, it is mentioned that all of the users to be given a purchase offer and those who are willing, buy the product(s). In the third option, it is stated that there is no significant difference between the first and second options. Here, the first option has the most preference and 2105 users, i.e. $87 \%$ of them have selected it. In the second question, the first option asks if the users like to do a purchase, they will be offered to buy another product which is in line with his previously purchased one or someone who has similar behavior and bought the product before. In the second option, it is stated that there is no need to offer and the user buys the products if necessary. In the second option, it is mentioned that that there is no significant difference between the first and second options. Here, 2027 users, i.e. 84\% of the participants have preferred the first option. The results of the survey are presented in Figure 3 and Figure 4.

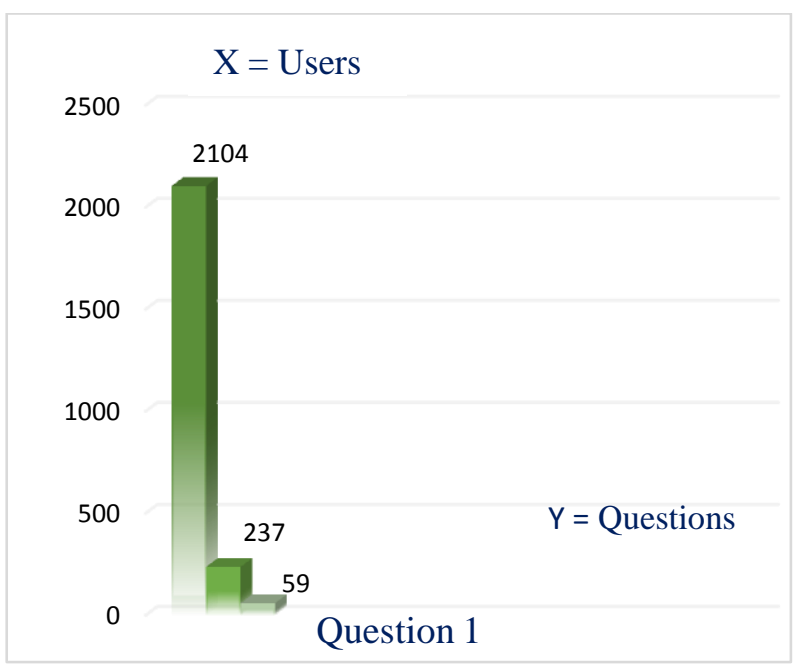

Fig 3: The diagram of the survey on Facebook for question 


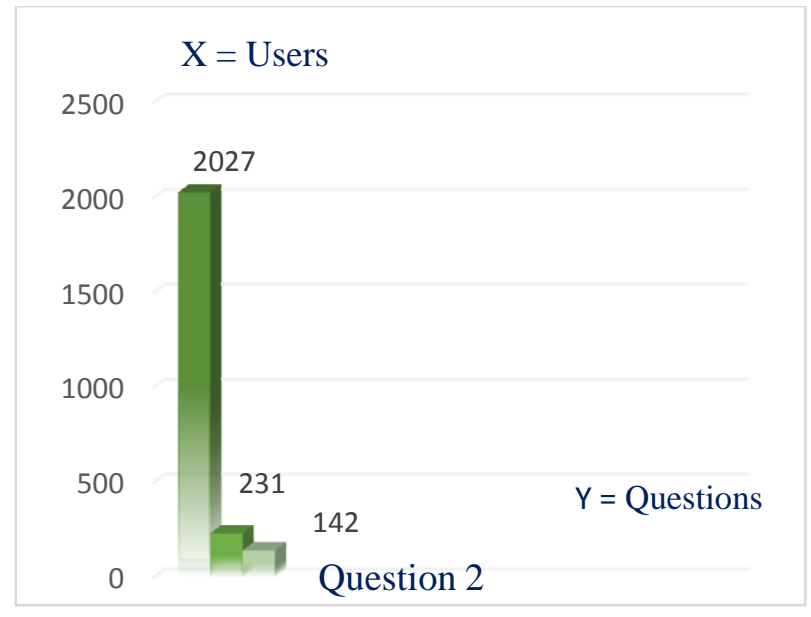

Fig 4: The diagram of the survey on Facebook for question 2

The results of the questions are close and show that most of the Facebook users like the performance of the recommender system and have accepted the offer(s) provided by it.

\section{CONCLUSION}

The proposed recommender system in the present study is designed based on the users' likes on Facebook. This can direct the presentation of the contents to the users and according to their behavior and interests; they are offered to buy a product that has the highest level of compatibility with their profile. If the usage conditions of the product are compatible with the information of the user's profile, he distinguishes that the product will be useful for him. In regard with the second offer, all of the purchases of the users can be controlled and directed based on association rules and data mining techniques and they can be offered a product the is in line with their previously bought ones, whereby they get motivated to accept the offer. According to the results of evaluating the designed recommender system, it can be stated that the provision of the offers to the users has acceptable accuracy. Finally, this process can direct the provision of the offers to the users of social networks and that the proposed system can be utilized in all social networks where the users have a profile and the offers can cover a cast range of fields.

\section{REFERENCES}

[1] Dan Zarrella, Alison Zarrella ; The facebook marketing book ; Published by O'Reilly Media ; Printed in Canada ; 2011.

[2] Saman Forouzandeh, Heirsh Soltanpanah , Amir Sheikhahmadi (2014). Content marketing through data mining on Facebook social network. Webology, 11(1), Article $118 . \quad$ Available at: http://www.webology.org/2014/v11n1/a118.pdf.

[3] Leila Esmaeili, Ramin Nasiri, Behrouz Minaei-Bidgoli; Applying Personalized Recommendation for Social
Network Marketing ; International Journal of Online Marketing ; Volume 2, Issue 1. ; 2012.

[4] Ruth Garcia , Xavier Amatriain ; Weighted Content Based Methods for Recommending Connections in Online Social Networks ; Proceedings of the 2nd ACM RecSys'10 Workshop on Recommender Systems and the Social Web - Barcelona, 2010.

[5] Fijałkowski Damian , Radosław Zatoka ; An architecture of a Web recommender system using social network user profiles for e-commerce ; Proceedings of the Federated Conference on Computer Science and Information Systems. pp. 287-290 - IEEE; 2011.

[6] Hajime Hotta , Masafumi Hagiwara ; User Profiling System Using Social Networks for Recommendation ; 8th International Symposium on Advanced Intelligent Systems (ISIS 2007) ; 2007.

[7] Cleomar Valois B. Jr , Marcius Armada de Oliveira; Recommender Systems in Social Networks ; Journal of Information Systems and Technology Management (JISTEM); Vol. 8, No. 3, pp. 681-716; 2011.

[8] Fatemeh Khoshnood, Mehregan Mahdavi, Maedeh Kiani sarkaleh ; Desinging a Recommender System Based and Social Networks and Location Based Services ; International Journal of Managing Information Technology (IJMIT) ; Vol.4, No.4; 2012.

[9] Jianming He , Wesley W. Chu ; A Social Network-Based Recommender System (SNRS) ; Springer, Vol. 12, pp. 47-74; 2010.

[10] Elnaz Davoodi, Mohsen Afsharchi, Keivan Kianmehr ; A Social Network-based Approach to Expert Recommendation System ; Hybrid Artificial Intelligent Systems - 7th International Conference, HAIS 2012; 2012.

[11] Xin Li , Guandong Xu, Enhong Chen, Yu Zong; Learning recency based comparative choice towards point-of-interest recommendation ; journal of Expert Systems with Applications - elsevier ; 2015.

[12] Y. Qu, X. Yang , T. Huang ; Survey of Recommendation System and Algorithms ; EE 380 L: DataMining ; 2000.

[13] J. S. Breese, D. Heckerman, C. M. Kadie ; Empirical analysis of predictive algorithms for collaborative filtering ; Fourteenth Annual Conference on Uncertainty in Artificial Intelligence (pp. 43-52). Morgan Kaufmann; 1998.

[14] Francesco Ricci, Lior Rokach, Bracha Shapira, Paul B. Kantor; Recommender Systems Handbook. $1^{\text {st }}$ Edition. New York: Springer.; 2011.

[15] Jiawei Han and Micheline Kamber ; Data Mining: Concepts and Techniques ; Second Edition, Diane Cerra; Elsevier Inc - 13: 978-1-55860-901-3 ; 2006. 